\title{
Mulheres, policiais, militares: uma análise histórica das primeiras PMs paranaenses
}

\author{
Entre o mito e a modernidade: a \\ entrada de mulheres na Polícia \\ Militar do Paraná
}

MOREIRA, Rosemeri

Guarapuava: Editora UNICENTRO, 2016

Entre o mito e a modernidade: a entrada de mulheres na Polícia Militar do Paraná, publicado em 2016, é proveniente da pesquisa de mestrado em História defendida por Rosemeri Moreira, em 2007, na Universidade Estadual de Maringá/PR. A despeito do intervalo de quase uma década entre o desenvolvimento da pesquisa e sua publicação pela Editora da UNICENTRO, O mérito da obra no que respeita à inovação temática e à articulação de categorias analíticas permanece indiscutível: mulheres, polícia, instituições militares, corpo militarizado - noções pouco interseccionadas tanto na historiografia, quanto nos estudos feministas - são postos em suspensão e desconstruídos como concepções que ganham nuances específicas na medida em que integram o processo histórico.

Rosemeri Moreira é feminista e historiadora, com pesquisas voltadas ao estudo das teorias feministas contemporâneas, à investigação das instituições militares imbricadas com a história do corpo, das masculinidades e das mulheres. $\mathrm{Na}$ obra em questão, a partir dos pressupostos analíiticos de gênero (Joan SCOI, 1995), a autora investiga um momento de (des)encontro entre a instituição Polícia Militar, concebida historicamente como espaço de atuação exclusivamente masculino, e a emergência de um sujeito feminino multifacetado, prescrito no discurso legal, que deveria ocupar a caserna e as ruas. Em tempo, a pesquisadora invoca as noções conceituais de habitus sexuado e habitus militar, propostas por Pierre Bourdieu, ${ }^{1}$ com o intuito de evidenciar os deslocamentos necessários para se construir, a partir de um corpo civil visto como feminino, um novo corpo militar que deveria preservar uma feminilidade controlada. Empiricamente, tratase do processo de entrada das mulheres na Polícia Militar do Paraná, nos anos finais de 1970 e na década seguinte.

No primeiro (e mais longo) capítulo, "Pela letra da lei: a invenção da mulher policial militar no Paraná", Moreira se debruça sobre os projetos de remodelação das forças repressoras do Estado, fomentados por fatores que articulavam interesses do poder público e debates culturais: em âmbito estadual, contingentes populacionais - boias-frias, desempregados, meninos de rua ganhavam visibilidade a partir dos processos de urbanização de Curitiba e demandavam controle do Estado; no que se refere ao Regime Militar, o período de distensão ensejou a necessidade de repensar a estrutura institucional, haja vista que a imagem estava comprometida com denúncias de tortura e violência; acrescentam-se, ainda, as discussões empreendidas pelos movimentos feministas que questionavam a desigualdade entre homens e mulheres, calcada na suposta inferioridade feminina e evidenciavam "[...] um outro discurso, uma outra fala, de outras vozes, entonações e lugares em que mulher/ mulheres passam a ser a tônica de ligação entre igualdade e modernidade" (Rosemeri MOREIRA, 2016, p. 68).

Documentos normativos - dentre os quais se destacam a LOB (Lei de Organização Básica da PMPR, de 1976, que atribuiu legalidade à existência de mulheres policiais militares) e o Decreto Estadual n. 3238/77 (que criou o Pelotão 
de Polícia Feminina/PR) - instituíram um novo sujeito no interior da PMPR: sujeito idealizado que teria como missão humanizar as forças policiais, afinal, a ele estavam atrelados a maternidade e o cuidado com o outro, compreendidos como características naturais das mulheres. Às mulheres policiais militares cumpriria mediar a relação entre a instituição viril e os outros - notadamente, crianças, idosos e outras mulheres contribuindo, dessa forma, para a modernização Polícia Militar paranaense.

No segundo capítulo, "Mulheres na caserna", a idealização da feminilidade prescrita nos documentos oficiais foi confrontada com as mulheres de carne e osso. Entre o ideal militar historicamente, viril e masculinizado - e as idealizações oficiais de uma mulher caracterizada com base em concepções binárias de gênero imaginada como complementaridade do masculino, estavam as primeiras praças da Polícia Militar paranaense. A transformação do corpo civil e feminino em corpo militar é perpassada por questões difíceis de equacionar: como incluir mulheres nos quadros da instituição sem comprometer a virilidade da corporação? Como manter as características maternas e de cuidado entendidas como próprias das mulheres, razão primeira de a PMPR incorporar esses novos sujeitos ao quadro, e, ao mesmo tempo, militarizá-las?

Para Rosemeri Moreira, a tensão instaurada entre um ideal militar e um ideal feminino, é detectável no esforço contínuo por parte da instituição Polícia Militar em conter e manter os corpos dessas mulheres na linha tênue entre feminilidade e militarismo; tarefa árdua e, por vezes, contraditória que ocupou os meses de treinamento das primeiras PMs paranaenses. São criadas regras e proibições específicas para as policiais mulheres, às quais se ordenava, por exemplo, a forma de usar o cabelo - visto como símbolo maior da feminilidade -, orientava-se sobre o comportamento adequado em público e no interior da caserna, os espaços de circulação, as companhias, hábitos e trajes que deveriam manter; ao mesmo tempo, exigia-se que as policiais usassem o primeiro nome, afirmando sua feminilidade, e não tivessem encargos familiares, ainda que devessem permanecer maternais. A despeito do esforço em caracterizá-las como ajudantes dos policiais homens de modo a delimitar seu espaço de atuação, quando apresentadas à imprensa (ainda durante o período de treinamento) as mulheres policiais militares surgiram, de acordo com a pesquisadora, com postura e expressão militarizada, um sujeito que compunha o nós militar de maneira homogênea e era perfeitamente "capaz de ser agente da violência estatal" (MOREIRA, 2016, p. 130).

Se os primeiros contatos entre a caserna e as mulheres a serem militarizadas sugerem um embate mudo entre elas e a Polícia Militar, a presença de policiais militares femininas nas ruas anunciou rompimentos. Em "Compondo as ruas e a si mesmas" (título do terceiro capítulo), a autora discute o momento em que as policiais mulheres passam, efetivamente, a ocupar as ruas. Após uma formatura de gala em que os corpos das PMs tiveram a oportunidade de comprovar a interiorização do militarismo através da execução ordem unida sem comando, a urbanizada Curitiba recebeu seu contingente de mulheres protetoras: fardas diferenciadas para preservar a feminilidade, bolsas que escondiam a arma, objeto viril agora sob a posse de mulheres, posições para sentar, caminhar e descansar. A presença em espaços em que podiam observar e serem observadas ajudava a compor a imagem/missão das novas profissionais da instituição.

A autora argumenta que o projeto oficial, embora visasse estabelecer uma finalidade rígida para as atividades das mulheres policiais - a de humanizar a instituição e de atuar no controle de grupos entendidos como relativos à feminilidade -, não logrou controlar a experiência desses sujeitos. Uma vez nas ruas, esse sujeito feminino militarizado passou por deslocamentos e se constituiu em mulher-fronteira: entre as normativas que buscavam restringir sua ação e o trabalho cotidiano, essas mulheres romperam, na prática, com as prescrições do discurso oficial: usaram armas à mostra, trabalharam em espaços e horários destinados aos homens policiais, negaram-se ao assistencialismo, construíram uma pauta de reivindicações que atendessem os interesses desse novo grupo; em suma, reinventaram tanto o ethos militarizado quanto sua suposta feminilidade.

O livro tem, possivelmente, como primeiros leitores pesquisadores contemporâneos dos temas transversais sintetizados acima; contudo, acrescentaria que permite questionamentos que ultrapassam o objeto, temática e temporalidade recrutados pela autora e que reclamam outros olhares perscrutadores. A relação entre a (des)militarização das forças repressoras do Estado e a experiência democrática brasileira - pauta contemporânea -, possui facetas que vão além dos sujeitos geralmente evidenciados, como sugere a análise da pesquisadora. Além disso, não sem esforço, desencadeia outra questão, que se refere ao silêncio acadêmico diante das 
atuações femininas em órgãos de repressão revestidos de características conservadoras: em que medida as escolhas políticas dos movimentos feministas, em muitos casos sediados em instituições de pesquisa, contribuem para esse silêncio? Em tempos de autocrítica dos programas feministas, o texto de Rosemeri Moreira, embora não responda essas questões, evidencia a necessidade catalisar tais problematizações nos debates contemporâneos.

\section{Notas}

1 Habitus é uma noção conceitual frequente na obra analítica de Pierre Bourdieu. No livro resenhado a autora recorre, principalmente, às definições mais específicas presentes em: A economia das trocas simbólicas (2004) e A Dominação Masculina (2007).

\section{Referências}

BOURDIEU, Pierre. A dominação masculina. Rio de Janeiro: Bertrand Brasil, 2007.

A economia das trocas simbólicas. São Paulo: Perspectiva, 2004.

SCOIT, Joan. "Gênero: uma categoria útil para a análise histórica". Educação \& Realidade, Porto Alegre, v. 20, n. 2, p. 71-99, jul.-dez. 1995.
Disponível: http://seer.ufrgs.br/index.php/ educacaoerealidade/article/view/71721/ 40667. Acesso: 29/03/2017.

[Recebida em 02/1 1/2016 e aprovada em 07/02/2017]

Gilvana de Fátima Figueiredo Gomes Universidade Estadual Paulista "Júlio de Mesquita Filho", Assis, SP, Brasil

Gilvana de Fátima Figueiredo Gomes é (fichamentoshistoria@gmail.com) graduada em História pela Universidade Estadual do CentroOeste (Guarapuava/PR, 2014), doutoranda do Programa em História - Linha História e Sociedade - da Universidade Estadual Paulista "Júlio de Mesquita Filho" (Assis/SP). Desenvolve pesquisas sobre História da Imprensa, com especial interesse à imprensa feminina; investiga, ainda, História e historiografia paranaense, intelectuais e cultura política. Tem interesse pela história dos Movimentos Feministas no Brasil e as teorias feministas contemporâneas. 